Síntese - Rev. de Filosofia

v. 31 N. 99 (2004): 107-131

\title{
A POLÊMICA EM TORNO AO PSICOLOGISMO DE BOLZANO A HEIDEGGER
}

\author{
Mario Ariel González Porta \\ $\mathrm{PUC}-\mathrm{SP}$ \\ “... pois, na filosofia, precisamente os \\ problemas estão intimamente vinculados \\ e um se desprende e se desencadeia do outro..."1
}

Resumo: A crítica do psicologismo constitui o tema da Dissertatio heideggeriana, um texto citado regularmente, porém pouco estudado. A carência principal constatável é a deficiente atenção ao contexto no qual o mesmo foi escrito. Este contexto, não obstante, é elemento imprescindível para uma adequada valorização do escrito que explicite o que ele representa para a filosofia alemã do momento e para a fixação do caminho do pensar heideggeriano ao "Ser e tempo". As linhas que se seguem estabelecem as bases para 0 tratamento de ambas as questões, na medida em que reconstroem o mencionado contexto em uma ampla perspectiva histórico-evolutiva que, ainda que sintética, pontua as inflexões decisivas que a temática do psicologismo experimenta de Bolzano a Husserl.

Palavras-chave: Heidegger, psicologismo, platonismo lógico, neokantismo, filosofia da vida (Lebensphilosophie).

${ }^{1}$ Tr. do autor: “...da in der Philosophie gerade die Probleme innig verwachsen sind und eines das andere aus- und ablöst..." (Martin Heidegger: "Neuere Forschungen über Logik". Em: "Gesamtausgabe. 1 Abteilung. Band I: Frühe Schriften" Frankfurt, Vittorio Klostermann, 1972. pp . 17-45 (NFL,17)). 
Abstract: The criticism of psychologism constitutes the theme of Heidegger's Dissertatio, a text that is often quoted, but rarely studied. The main noticeable deficiency is the insufficient attention given to the context in which it was written. This context is, nevertheless, an indispensable element to an adequate appraisal of the writing in order to make explicit what it represents to German philosophy at that moment and to determine the path of Heidegger's thought towards "Being and Time". The lines below establish the basis for dealing with both questions, as the context mentioned above is reconstructed in an ample historical-evolutive perspective that, in spite of being synthetic, points out the decisive inflections that the theme of psychologism experiences from Bolzano to Husserl.

Key words: Heidegger, psychologism, logical platonism, neokantianism, life philosophy (Lebensphilosophie)

\section{Introdução}

A minha pesquisa não se concentra num autor, mas num tema, que pode ser resumido em cinco pontos²:

1. Parto da convicção da unidade da filosofia contemporânea na diversidade de suas tendências fundamentais (ou seja, filosofia analítica e hermenêutico-fenomenológica) ${ }^{3}$.

\footnotetext{
${ }^{2}$ Visando abreviar o texto eu suprimi todas as citações e referências naqueles casos em que as mesmas são indicadas e/ou analisadas em outros textos de minha autoria. As citações e referências a Heidegger ou a outros pensadores não indicadas e/ou analisados nos trabalhos já publicados, serão introduzidas em notas correspondentes. A lista de trabalhos referidos é a seguinte:

a) "Reseña de 'Konstitution und Gegebenheit bei H. Rickert' de Lothar Kuttig". Estudios bibliográficos de Filosofía, Sevilla, v.10, p. 236-238, 1989.

b) "Transzendentaler Objektivismus (Bruno Bauchs Verarbeitung des Themas der Subjektivität und ihre Stellung innerhalb der Neukantischen Bewegung". Frankfurt: Peter Lang, 1990 (392 pp.).

c) "Los orígenes de la virada antipsicologista en Husserl" (La reseña a Schröder de 1891 revisada). Thémata. Revista de Filosofía. Sevilla: v. 21, p. 85-116, 1999

d) "La cuestión noética en Frege, su concepto de intencionalidad y su influencia sobre Husserl". Thémata. Revista de Filosofía, Sevilla: v. 24, p. 83-114, 2000

e) "Cassirer e a filosofia das formas simbólicas". Ethica, Rio de J aneiro, v. 8, n. 1, p. 128-152, 2001.

f) "Franz Brentano. Equivocidad del Ser y objeto intencional". Kriterion. Minas Gerais, v. XLIII, n. 105, p. 97-118, 2002.

g) "Platonismo e intencionalidade: a propósito de Bernhard Bolzano. Primeira Parte". Síntese. Nova Fase. Minas Gerais, v. 29, n. 94, p.251-275, 2002.

h) "Platonismo e intencionalidade: a propósito de Bernhard Bolzano. Segunda Parte". Síntese. Nova Fase. Minas Gerais, v. 29, n. 94, p.85-106, 2003.

3 ¿"Que és 'filosofía contemporánea"'? (La unidad de la filosofía contemporánea desde el punto de vista de la historia de la filosofía. Transformação (Revista de Filosofia). São Paulo, v. 25, pp. 29-52, 2002.
} 
2. Se a tese anterior é prioritariamente sistemática, ela possui, porém, um forte conteúdo histórico-filosófico. É nele que concentro a minha atenção.

3. 0 que me proponho é reconstruir as origens comuns às duas tradições mencionadas, assim como as interações efetivas que as mesmas apresentam através do seu desenvolvimento.

4. Em tal perspectiva, uma atenção especial merecem os temas que ocupam um lugar decisivo em ambas, no duplo sentido sistemático e factual.

5. Um desses temas é a crítica ao psicologismo.

Dela parte a reflexão heideggeriana ${ }^{4}$ e, eu me atreveria a dizer, ela tem um papel decisivo no caminho a "Sein und Zeit" (SZ)5. Meu ponto de chegada será o ponto de partida de Heidegger. Não vou, então, nem me concentrar na análise do texto de 1913, nem considerar o mesmo na sua totalidade. 0 que farei será situá-lo no seu contexto, acompanhando a grandes traços a evolução da luta antipsicologista de forma tal que evidencie o que o texto heideggeriano representou na mesma. Dado que o tema anunciado implica passar por diversos autores e escolas, o "perigo" de superficialidade e mera agregação é iminente. Por tal motivo, limitarei minha análise a focalizar o giro característico que efetua cada um dos autores e escolas mencionados neste longo percurso.

Facilitará a exposição que segue, lembrar uma questão e definir dois conceitos:

1. A questão aludida é a referente à realidade do mundo externo ou à possibilidade de nosso acesso ao mesmo a partir da imanência da consciência, questão esta que, como é sabido, ocupa lugar de destaque na filosofia moderna.

2. Entenderemos por "realismo lógico" uma teoria de extrema difusão no século XIX segundo a qual se afirma a existência "em si" (isto é, independente da subjetividade) de objetos e estruturas lógicas não menos que a nossa capacidade de conhecê-las ${ }^{6}$.

3. 0 termo "psicologismo" tem uma infinidade de sentidos e o chamado "problema do psicologismo" contém, em realidade, vários problemas. Pode-se diferenciar três tipos de psicologismo: o lógico, o "semântico" e o "epistemológico". O psicologismo lógico é uma teoria que se propõe assimilar a lógica à psicologia, concebendo a primeira como parte da segunda e negando, desta forma, a existência de entidades e estruturas

\footnotetext{
"A sua tese de doutorado leva por título "Die Lehre vom Urteil im Psychologismus"

${ }^{5}$ As citações a SZ se referem á edição de Max Niemeyer (Tübingen, 1986) que é uma versão inalterada da $15 a$ edição.

${ }^{6}$ Aquilo que no século XIX chamamos "realismo lógico" é, no fundo, um certo tipo de platonismo.
} 
propriamente lógicas. 0 psicologismo semântico consiste em reduzir significações lingüísticas a entidades psicológicas. 0 psicologismo epistemológico, finalmente, reduz o conhecimento (e/ ou a validade epistêmica) a um processo psicológico.

Psicologismo e realismo lógico são opostos. Eles constituem os atores do drama que vamos seguir e o problema da transcendência, em nova variante, o palco no qual este drama vai se desenvolver.

Clarificados os conceitos básicos, vou a minha tese: o realismo lógico e a crítica ao psicologismo vinculada ao mesmo, longe de implicar um desterro da questão da subjetividade como tema filosófico, remetendo-a a psicologia, a tornam necessária desde o ponto de vista sistemático e não se sustentam sem ela. A tese sistemática é confirmada pela análise histórica. Esta será o prespressuposto da minha interpretação do trabalho juvenil de Heidegger já mencionado.

\section{Bolzano}

\section{1. "A Teoria da ciência" ("Die Wissenschaftslehre")}

Bolzano é considerado tanto a origem da chamada virada semântica (semantic turn), quanto do realismo lógico, existindo entre ambos um forte elo. Ele pode ser considerado, também, o início do antipsicologismo, ainda que com uma importante precisão. 0 oponente principal de Bolzano é o ceticismo e, por decorrência, o relativismo em todas as suas formas; o psicologismo em particular, não constitui o tema central, nem é objeto de crítica expressa. Ele é, simplesmente, com a introdução de cada novo conceito e cada nova tese "executado" de modo sumário.

A Wissenschaftslehre no sentido próprio trata do conteúdo objetivo da ciência e de suas inter-relações, entre as quais ocupa um lugar de destaque a demonstração. A ela se somam, como esferas igualmente objetivas, a teoria das verdades fundamentais e a dos elementos. Nestas três disciplinas nada nos é dito sobre um sujeito cognoscente. Este será tematizado pela "teoria do conhecimento" (Erkenntnislehre), entendida como a parte da teoria da ciência que trata das condições nas quais a verdade pode ser conhecida por nós, sujeitos humanos. A distinção bolzaniana entre teoria do conhecimento e da ciência marca de forma explícita um corte com a tradição moderna e antecipa a "Theory of science" contemporânea. 
A tese central da Wissenschaftslehre reza: "existem verdades em si" (Wahrheiten an sich), isto é: há verdades independentes do homem e inclusive, de Deus; o sujeito pode captá-las, mas não produzi-las. Do conceito de "verdades em si", segue-se 0 de "proposição em si" (Satz an sich). Verdades em si supõem "proposições em si", pois elas não são outra coisa que proposições em si que são verdadeiras. Proposições em si são o sentido de enunciados pensados ou expressados, um sentido, porém, que não pressupõe atos psicológicos ou lingüísticos. Proposições em si são tão objetivas e independentes de qualquer sujeito quanto verdades em si. Além das já mencionadas, elas possuem outras três qualidades essenciais:

1. Proposições em si não são simples, mas sempre articuladas; elas apresentam uma estrutura na qual é possível diferenciar elementos, as "representações em si" (Vorstellungen an sich).

2. Proposições em si são as depositárias originais da verdade e falsidade (ou: essencialmente capazes de ser verdadeiras ou falsas).

3. Proposições em si são bipolares, ou seja, elas não só são as essenciais depositárias de verdade ou falsidade, mas necessariamente ou um ou outro.

Finalmente, o ser em sentido próprio é o ser "real" (wirklich). Ser-real significa estar submetido a relações de causação (wirken). o que "existe", atua ou padece. Por esse motivo, Deus e os objetos espaço-temporais são reais; verdades, proposições e representações em si, pelo contrário, não 0 são?

\subsection{Descobrindo dificuldades}

O primeiro crítico do realismo bolzaniano foi seu amigo e interlocutor epistolar, Franz Exner. Exner não era um lógico, mas um psicólogo, e nada tem a dizer sobre as doutrinas estritamente lógicas de Bolzano. Não obstante, é essa diferença de perspectiva entre ambos 0 que faz a sua crítica particularmente interessante. No centro da discussão entre Exner e Bolzano se situa a resistência do primeiro a aceitar verdades em si e todas as suas derivações. Conteúdos pensados não possuem nenhum tipo de existência fora do pensamento, mas só existem nele. Verdades e proposições em si não são mais que abstrações a partir de sujeitos psicológicos reais. Mas, se Exner concentra a sua análise em negar a existência de objetos lógicos, por momentos adota um ponto de vista sistematicamente mais interessante, a saber, o de questionar de princípio nossa possibilidade de aceder aos

\footnotetext{
${ }^{7}$ Observe-se: não se trata de diferenciar dois tipos ou duas esferas de "realidade" (por exemplo, um ser ideal e um ser sensível); o "em si", simplesmente, não é real.
} 
mesmos. Bolzano insiste com um tal radicalismo na absoluta heterogeneidade entre 0 em si e o subjetivo, que obviamente termina colocando o problema da sua relação. Se o sujeito, por um lado, é real e verdades em si, por outro, não, então:

1. Como um sujeito "real" pode apreender algo que não é real, mais ainda, que não é real "nele" de forma alguma?

2. Como é possível que algo que não existe seja apreendido por algo que existe?

3. Que significa aqui (em sentido não metafórico) "apreensão" (Auffassung)?

4. Como acedemos à verdade objetiva?

5. Que legitima fazer afirmações sobre a mesma?

Se, como observamos num começo, se encontra em Bolzano o claro início do realismo lógico e antipsicologismo, não é menos certo que está também presente nele a necessidade de uma reformulação da teoria do sujeito, uma necessidade que, na sua obra, se apresenta como problema ainda não resolvido de modo satisfatório. Bolzano não dispõe de uma teoria do sujeito coerente com o seu realismo lógico e que conteste as objeções de Exner. 0 que se pode encontrar em seus textos é uma perspectiva naturalista básica (na qual a explicação causal tem o primado) e que convive, se contradizendo, com alguns lampejos de uma concepção intencional que não passa de uma mera variante da "tese da imanência"8.

\section{Frege}

\subsection{As fases do antipsicologismo fregueano}

Ao contrário de Bolzano, a crítica expressa do psicologismo é tema central para o desenvolvimento do realismo lógico em Frege, ao passo que a questão do ceticismo permanece como derivada. Ora, pressupõe-se que 0 antipsicologismo acompanha o desenvolvimento filosófico fregueano desde um começo e se mantém - sem mudanças substanciais - até o final da sua vida. Não é assim. Três momentos podem ser diferençados a esse respeito, situados em torno aos anos 1879, 1884 e 1893, anos de publicação de "Begriffschrift", "Grundlagen der Arithmetik" e "Grundgesetze der Mathematik" respectivamente. Em 1879 Frege é um antipsicologista lógico,

${ }^{8}$ Veja-se 3.2.2. 
mas um psicologista semântico. Em 1884 a crítica ao psicologismo em todas as suas variantes torna-se tema central e se mantém nessa posição até a sua morte. Não obstante, existe uma significativa diferença no antipsicologismo de 1884 e de 1893. A partir desta data, Frege deixa entrever um interesse pelo "problema de Exner" e esboça uma tentativa de solução.

Não é improvável que essa significativa mudança esteja vinculada a sua polêmica com Kerry, a qual acontece cerca de 1890. A opinião que prima entre os estudiosos é que Kerry era um lógico pouco expressivo, a quem Frege critica de modo contundente em "Begriff und Gegenstand". Na realidade, isto é tão-só uma parte da história. A relação conceito-objeto não foi 0 único tema discutido na polêmica nem constituiu o núcleo da mesma. Kerry, que era um discípulo de Brentano, coloca Frege frente à mesma dificuldade que já antes Exner havia colocado a Bolzano. Ante a acusação fregueana de "psicologismo", Kerry responde que não se deve temer que, pelo fato de se buscar estabelecer as condições subjetivas dos objetos da aritmética, esta se torne psicologia. Muito mais frutífero que um mero horror subjetivo (a ironia é do próprio Kerry) é ver como, a partir do subjetivo, do qual de todas formas tem que tomar origem nosso conhecimento, surge algo objetivamente válido. A tarefa é mostrar como, mediante "trabalho psíquico" (psychische Arbeit), surgem estruturas (por exemplo, o número) que pretendem ter validez objetiva. Muitas são as precisões que exigiria o texto de Kerry e muitas as distinções que seriam necessárias para chegar a uma claridade definitiva. Sem embargo, se os seus argumentos e a sua solução distam de ser transparentes, o problema geral ao qual, porém, aponta (ou, pelo menos, o núcleo do mesmo) não deixa de ser legítimo.

Em nenhum momento Frege responde explicitamente à questão levantada por Kerry; bem poderia se pensar então, que ele não concedeu importância à mesma e que tudo não passa de uma curiosidade. Não obstante, existem algumas boas razões para pensar que não foi assim. Em 1893, no prólogo das "Grundgesetze ...", o alvo da crítica antipsicologista será Erdmann. 0 porquê Frege elege a Erdmann se deve, em parte, a que a "Logik" deste acaba de ser publicada, obtendo uma calorosa recepção. Mas quiçá também se deva a que Erdmann continue a desenvolver o projeto de Kerry de uma teoria do "trabalho psíquico". Ainda mais decisivo que esse fato é atender ao conteúdo da crítica fregueana. Se compararmos a refutação do psicologismo de "Grundgesetze ..." com a de "Grundlage ..." salta à vista uma diferença: em "Grundgesetze ..." não só se insiste na distinção entre o subjetivo e o objetivo, mas todo 0 argumento de Frege está literalmente baseado na questão da "passagem do subjetivo ao objetivo". Frege dispõe agora de um caminho para, pelo menos, oferecer a Kerry um claro contraargumento sob a forma de explicitar como a sua pergunta não deve colocar-se e pela revisão de quais pressupostos ela pode responder-se. 
Ora, para entender a resposta de Frege temos que, voltando à sua segunda etapa, observar que sua crítica ao psicologismo tem dois aspectos: um metódico, outro sistemático.

\subsection{As duas críticas ao psicologismo}

\subsubsection{A crítica metódica ao psicologismo}

A crítica fregueana ao psicologismo aponta a distinguir o âmbito de trabaIho de duas disciplinas: lógica e psicologia, e possui, portanto, o caráter de uma delimitação metódica. Sua justificação arranca da própria possibilidade da distinção que ela estabelece. Que aqui seja possível distinguir, é prova suficiente de que estamos frente a duas coisas diversas. Segundo uma idéia usual no século XIX, a lógica se ocupa com as leis do pensamento. Agora bem, com o pensamento também se ocupa a psicologia. E então? Obviamente, nos dois casos se trata de conceitos de "pensamento" diferentes. Poderíamos evidenciar esta diferença falando em um caso do pensar como ato, no outro, do pensamento como conteúdo do ato ou, mais precisamente (já que o conteúdo mesmo pode ainda ser visto como realidade psicológica) como o conteúdo "objetivo" do ato. Quando dizemos que a lógica se ocupa das leis do pensamento, devemos entender por "pensamento" não 0 ato de pensar (ou qualquer realidade psicológica), mas 0 pensamento em sentido objetivo. Pelo contrário, a psicologia se ocupa com 0 ato de pensar enquanto evento.

Se partirmos da idéia de que o antipsicologismo fregueano é exclusivamente metódico, se sugere que o psicologismo é uma mera confusão, do que se segue que a correção do erro psicologista tem um caráter essencialmente negativo. Sendo isto assim, dado que a lógica se ocupa com o pensamento e suas relações objetivas, é absolutamente indiferente para a mesma como esses pensamentos sejam "captados". A "captação do pensamento" é uma questão psicológica; a relação entre lógica e psicologia, puramente negativa.

\subsubsection{A crítica teórica ao psicologismo}

Porém, nem o antipsicologismo fregueano é puramente metodológico, nem o psicologismo que ele critica é uma mera confusão. Em realidade, ainda que o psicologismo seja uma teoria falsa, ele é uma teoria positiva que, como tal, tem que ser criticada e substituída por uma outra. Mas, o que é o psicologismo? A assimilação da lógica como disciplina à psicologia como disciplina é conseqüência não só (e não sempre) da confusão das leis lógicas com as psicológicas, mas da redução de umas às outras, redução que, pela sua vez, não afeta só as leis, mas a toda entidade que possa ser con- 
siderada especificamente lógica. A essência do psicologismo, pois, é o reducionismo: o psicologismo não necessariamente confunde, mas sempre reduz.

A disputa entre psicologismo e antipsicologismo se concentra no reconhecimento ou desconhecimento de uma esfera lógica específica e autônoma ou, dito de outra forma, no reconhecimento ou desconhecimento de uma diferença entre 0 objetivo e 0 subjetivo. 0 psicologismo reduz o lógico ao psicológico porque reduz o objetivo ao subjetivo. A conseqüência disto é 0 idealismo, o solipsismo e, em definitivo, o ceticismo. 0 motivo fundamental da crítica fregueana ao psicologismo é, pois, epistemológico: o psicologismo conduz a uma negação da objetividade.

0 psicologismo não é fruto de uma mera confusão; ele é uma teoria falsa. Em que consiste esta teoria? Basicamente em três teses:

1. Tudo o que é objetivo, é real. Verdade supõe realidade. A realidade é o substrato da verdade do ser verdadeiro.

2. Tudo o que é, é real, sendo que o real é físico ou psicológico ${ }^{9}$. Ora, operadores lógicos, números, significados de palavras, sentidos de enunciados etc., não são obviamente objetos físicos, pois não estão dados no espaço nem podem ser percebidos pelos sentidos. Em conseqüência, já que não têm realidade "externa", têm que ter algum tipo de realidade "interna". Eles são entidades psíquicas (Vorstellungen).

3. Só temos acesso direto às nossas próprias representações. Esta tese é conhecida como "princípio da imanência" e deve a sua formulação historicamente decisiva a Locke. Ela está em plena validez no século XIX sendo explicitamente aceita por quase a totalidade dos autores, de Erdman a Sigwart, de Fischer a Lotze.

Observe-se que, enquanto a primeira e a segunda tese são ontológicas (ou seja, referem-se a "o que há" ou a que tipos de objetos existem), a terceira é "epistemológica" (ou "noética"), ou seja, se refere àquilo que podemos conhecer ou "captar" (fassen, auffassen). A importância desta distinção se tornará evidente nas linhas que seguem.

O psicologismo é, sem dúvida, uma doutrina ontológica na medida em que nega a existência de um certo tipo de entidades ou as reduz a outras (é dizer: assimila entidades lógicas (ideais) a entidades psicológicas (reais)). Mas, ele é também uma doutrina "epistemológica" que nega a objetividade, tanto porque nega a existência de certos objetos, quanto porque faz impossível o nosso acesso aos mesmos. Essa epistemologia, pela sua vez,

\footnotetext{
${ }^{9} \mathrm{O}$ naturalismo é uma tese usual na época de Frege. Por isso, um real metafísico (por exemplo, Deus), não preocupa; de todas formas, o mesmo valeria para ele.
} 
está imbricada numa teoria do sujeito, a qual se funda no "princípio da imanência".

Como resulta óbvio a partir da explicitação do contra-argumento psicologista, é extremamente importante para uma teoria não-psicologista positiva diferenciar nele duas teses e compreender que estas pertencem a diferentes esferas, pois, deste modo, fica claro que o psicologismo não é superado negando apenas a tese ontológica.

\subsection{A superação do psicologismo}

A identificação dos dois pressupostos básicos do psicologismo vai junto com a afirmação de seus contrários. Um deles já estava afirmado explicitamente em Bolzano, o segundo não. Isto faz uma importante diferença. Recapitulemos: que todo o objetivo tem que ser real é um pressuposto gratuito refutado pela existência da matemática e pela própria linguagem. Real e objetivo não são sinônimos. 0 reducionismo psicologista é a conseqüência de não poder aceitar a idéia de algo objetivo que não é real. Não obstante, é evidente que:

1. existe algo objetivo que, sem embargo, não é real;

2. somos capazes de conhecer esse objetivo não-real.

Se afirmo que existe um reino de objetos transcendentes e não-reais que, não obstante, são captados por mim, reaparece o "problema de Exner". $\mathrm{Mas}$, agora se torna claro que o psicologismo não meramente consiste em negar a existência de certos objetos ideais - sobre a base da consideração de que tudo é objetivo e real -. Ele diz, também, com isto e por isto, que tudo no sujeito é real, que a consciência só tem acesso àquilo que é real "nela".

Ainda que o psicologismo seja uma teoria falsa, esta é internamente coerente e oferece respostas simples a problemas complexos. Para o psicologismo não há dificuldade alguma em explicar como o sujeito capta o objeto, pois o objeto não é outra coisa que uma Vorstellung e uma Vorstellung, por definição, é algo "no" sujeito. Esta vantagem do psicologismo não foi vista meramente por Exner ou por Kerry em contextos polêmicos e de modo circunstancial; em muitos autores psicologistas é explorada como forte argumento a favor da própria tese. Assim é, por exemplo, em um dos psicologistas mais extremos: Theodor Lipps (que, como muitos outros, não recebia críticas passivamente, mas contra-argumentava baseando-se nas dificuldades da tese contrária).

O psicologismo não só reduz o objetivo ao subjetivo, mas o faz porque parte de uma falsa teoria da subjetividade. Se isto é assim, ele nunca é 
totalmente superado quando o seu oponente se contenta em negá-lo sem revisar a fonte da qual ele se nutre. Justamente por isso, justamente porque um "mero antipsicologismo" concede ao psicologismo sua idéia de subjetividade, este renasce das cinzas como verdadeira Fênix. Se a teoria psicologista da subjetividade fosse certa (ainda que a sua teoria do objeto falsa e existisse um reino lógico ideal) não teríamos acesso ao mesmo. Ele seria, para nós, algo assim como os deuses de Epicuro. Em suma, não se pode pretender negar o psicologismo e manter ao mesmo tempo a sua concepção do sujeito. Um antipsicologismo conseqüente têm que propor uma teoria alternativa.

Se sob determinados pressupostos o problema é insolúvel e, por outra parte, não estamos dispostos a cortar todo vínculo ao objetivo (dado que, em última instância, queremos "sair do subjetivo"), então não nos resta outro caminho senão negar estes pressupostos, ou seja, negar que o sujeito tem acesso unicamente às suas representações, aceitar que ele pode captar algo que não é a sua "representação".

\subsection{A teoria da subjetividade}

"Representação" é a tradução do termo alemão Vorstellung e este, a tradução do termo inglês "idea" e do francês "idée", sendo que o fato de que 0 termo "idea" perca o seu sentido platônico, para passar a indicar itens psicológicos, é característico da época moderna. Pois bem, Vorstellungen são:

- itens mentais (não necessariamente "re-presentativos" como o sugere a palavra portuguesa ou espanhola correspondente),

- que devem ser pensados em sentido literal como Bilder ou "quadrinhos mentais",

- que não só têm conteúdo sensível,

- mas que são, eles mesmos, entidades sensíveis (ainda que "internas") enquanto que estão submetidas ao tempo,

- e reais, pois uma Vorstellung é produto de uma causa e submetida, de princípio, a interações causais,

- que, justamente por isso, merecem ser chamadas de "conteúdos de consciência" (Bewusstseinsinhalte), os quais,

- por não serem auto-subsistentes precisam de um portador (Träger),

- sendo sempre "privadas": duas pessoas nunca podem ter a mesma Vorstellung.

Uma vez esclarecido o termo Vorstellung, estamos em condições de expor a teoria positiva da subjetividade que surge do texto fregueano. 0 que 
Bolzano chamava "Sätze an sich" é basicamente o que Frege chama de "Gedanken". Trata-se de objetos lógicos, independentes de todo sujeito e que possuem uma estrutura ou articulação, sendo os depositários originais da verdade ou falsidade. Agora bem, uma tese fregueana de extrema importância para a crítica do psicologismo consiste em definir o "pensar" (Denken) como "captar pensamentos" (Gedanken). O pensar não é, pois, de forma alguma, um fazer, mas um receber, um aceitar, uma absoluta passividade. Ele é, assim mesmo, algo heterogêneo tanto do ter representações como do efetuar algum tipo de atividade sobre as mesmas, tais como afirmá-las, negá-las ou "sintetizá-las". Representar e pensar são fenômenos essencialmente diferentes e irredutíveis um a outro.

Nós temos esclarecido o conceito de representação. É por oposição ao mesmo que podemos aprofundar a noção de pensamento (Gedanke). Ao contrário das representações, os pensamentos são inteligíveis, intersubjetivamente acessíveis e não reais. Estas duas últimas características têm uma íntima relação, sendo que o tema da intersubjetividade é central em Frege. Para o autor do "Begriffschrift" está fora de dúvida que existe um único número três e que só se captamos o mesmo, idêntico, número três, contradição de opiniões é possível; senão, cada um poderia fazer afirmações distintas sobre "o seu" número três. Se isto é assim, o número três não pode de modo algum ser real em mim (eu ter "meu" três). Que pensar e captar pensamentos implica não só que nossa consciência é capaz de captar algo não-sensível, mas que é capaz de captar algo que não é "real" nela e, mais ainda (e isto não é nada óbvio) algo que não pelo fato de ser captado se torna real na consciência, mas segue tão transcendente, tão exterior a esta, como se não fosse captado em absoluto.

Já que se denominou o princípio da imanência como "princípio de Locke", podemos chamar à sua negação "princípio de Frege". 0 eixo da posição fregueana é diferenciar entre o conteúdo (Bewusstseinsinhalt) e o objeto (Objekt, Gegenstand) da consciência. Se bem é certo que os conteúdos de consciência (Bewusstseinsinhalte) são sempre representações (e, como tais, reais e imanentes), não é certo, porém, que também o objeto da consciência o seja. Dito de modo pregnante: não é certo que a consciência só capta os próprios conteúdos, ou que só pode ser objeto da consciência o que é conteúdo da mesma. Objetos lógicos como, por ex., Gedanken (mas também números, classes etc.), são objetos da consciência, mas não por isso "conteúdos" da mesma.

A distinção fregueana entre o objetivo e o real é sempre considerada só na sua dimensão "objetiva", no marco da teoria dos três reinos, a qual por sua vez é pensada como teoria ontológica. Porém, à diferença entre 0 real e 0 objetivo no objeto corresponde, em Frege, a diferença entre 0 real e 0 objetivo no sujeito (ou seja, entre Inhalt e Gegenstand da consciência). Isto 
quer dizer: o mesmo princípio em base ao qual se refutou a redução psicologista do reino ideal, também desempenha um papel decisivo para refutar a teoria psicologista da subjetividade e, assim, para dar conta de nosso acesso a tal reino.

Contudo, ainda que o pensamento não seja real na consciência, o real na consciência é capaz de "apontar" a ele (hinzielen), e é aqui, nesta função de apontar, onde reencontramos as representações. Através de algo dado na consciência somos, pois, capazes de "apontar" a algo que não é parte real dela. 0 pensamento só está e pode "estar" na consciência como algo "apontado". Em suma, se chamamos as coisas pelo seu nome, o que Frege está propondo é uma concepção intencional do sujeito.

0 decisivo do ponto de vista do julgamento da teoria de Frege como teoria intencional não é, porém, o "hinzielen" (o fato de que a consciência só pode captar 0 objeto a partir de algo real em si). Não é isso o que faz dela uma teoria intencional interessante no contexto dos anos 90 . 0 verdadeiramente digno de nota são as particularidades da teoria intencional que Frege está defendendo. Ela coincide com o primeiro Brentano em sublinhar a direcionalidade da consciência, para diferir deste (coincidindo assim com os seus críticos e, principalmente, com Husserl) por negar, ao mesmo tempo, a tese da imanência.

\section{A Escola de Brentano}

Que a idéia de psicologia descritiva é fonte de inspiração da fenomenologia e que Husserl retoma o conceito de intencionalidade de Brentano, é algo que pode ser lido em qualquer história da filosofia. O que, em geral, se omite é, primeiro, que se Husserl faz do conceito brentaniano de intencionalidade um dos fundamentos da sua fenomenologia, ao mesmo tempo o submete a uma crítica decisiva e, segundo, que é justamente esta crítica, e não aquela identidade, o que dá a concepção intencional husserliana o seu perfil específico.

Porém, segundo uma interpretação amplamente difundida, inclusive entre os discípulos de Brentano (e com a qual não concordo), o conceito de intencionalidade brentaniano implica, na sua primeira formulação, que 0 objeto intencional está "na" consciência ou é imanente à mesma. É, pelo menos em parte, como conseqüência desta interpretação, que os discípulos de Brentano se sentiram obrigados a submeter o mestre a dura crítica. Höffler e Twardowski introduziram a distinção entre o objeto e o conteúdo da consciência (ou seja, entre Gegenstand e Inhalt ou Bewusstseinsinhalt); 
o primeiro é transcendente, o segundo, imanente à consciência, existindo nela de modo real; o primeiro é para onde a consciência se dirige, o segundo, o como ou através de que o faz.

\section{Husserl}

\subsection{Do psicologismo ao antipsicologismo}

Em 1894, na sua resenha do livro de Twardowsky "Inhalt und Gegenstand", Husserl concordará com a necessidade das distinções introduzidas, porém, efetuando por sua vez uma crítica que evidencia a necessidade de uma nova diferenciação, desta vez, entre o conteúdo real e o ideal, entre o papel da matéria do ato como presença efetiva na consciência e o meio ideal pelo qual nos referimos ao objeto.

Em seu primeiro trabalho "Philosophie der Arithmetik" (1891), Husserl se coloca como tarefa desenvolver uma teoria do número de acordo com os princípios metódicos da psicologia descritiva e em algumas passagens deixa claramente entrever que concede validez irrestrita ao princípio da imanência, considerando-0, implicitamente, não só compatível, mas inclusive necessário, a partir do conceito brentaniano de intencionalidade. De uma possível crítica a Brentano, ainda não exista neste texto o menor indício. Muito menos a Kerry, cujo programa de reconstrução do trabalho psíquico parece continuar.

Em 1884 Frege havia publicado "Grundlagen der Arithmetik". O jovem Husserl Ihe envia então uma carta junto com seu trabalho. Frege responde prometendo efetuar uma resenha do mesmo. A promessa será cumprida, mas a resenha é negativa (para não dizer absolutamente demolidora). 0 motivo principal da crítica fregueana é a acusação de psicologismo. Se levarmos em conta o que acabamos de dizer com respeito ao ensaio de Husserl, tal acusação (confundir o subjetivo e o objetivo) é justa. 0 próprio Husserl não tem mais que reconhecer a legitimidade da mesma. É a partir deste ano (1894), que ele começa a amadurecer seu antipsicologismo. A sua crítica a Twardowski assinala esta virada decisiva e inicia um caminho contínuo que o terminará levando as "Logische Untersuchungen" (LU) ${ }^{10}$.

\footnotetext{
10 Às citações são referidas à 4a. impressão de Max Nyemeyer (Tubingen, 1980), que é uma versão sem modificações da 2a. edição (1922).
} 
Em 1900 aparece o primeiro volume das LU, "Prolegomena zur reinen Logik"; o segundo, um ano depois. Os "Prolegomena" estão dedicados à crítica do psicologismo, a qual elaboram de um modo exaustivo e sistemático. 0 impacto do livro é tão grande que o antipsicologismo se converte no tema central de discussão e seus contemporâneos atribuem a Husserl 0 mérito de tê-lo superado definitivamente ${ }^{11}$.

Sendo consenso que a questão do psicologismo havia recebido o seu ponto final, qual não seria a surpresa nos círculos filosóficos quando, um ano depois, o segundo volume das LU, muda, aparentemente, o eixo e introduz uma nova perspectiva teórico-temática. Frente à existência do mundo lógico ideal, a questão é "agora" a de nosso acesso ao mesmo. Não era isto voltar ao psicologismo?

\subsection{O segundo volume das $L U$}

Na realidade, bastava ler com mínima atenção o prólogo de Husserl já ao primeiro volume da primeira edição para entender que os "Prolegomena zur reinen Logik", longe de solucionar problema algum, estavam dirigidos meramente a explicitar as bases fundamentais do mesmo, o qual devia ser solucionado no volume II. A crítica do psicologismo não era, pois, o objetivo da obra, mas um pressuposto (e nem sequer o único) com o qual as LU construíam o seu problema específico. Husserl escreve que, na medida em que a fundamentação psicológica da lógica e matemática fracassa por não conseguir dar conta da objetividade, ele se viu obrigado em medida crescente a reflexões críticas gerais sobre a essência da lógica e, em primeiro lugar, sobre a relação entre a subjetividade do conhecer e a objetividade do conteúdo conhecido12. As investigações sobre a lógica pura deverão ser, então, interrompidas para ganhar claridade a respeito das perguntas fundamentais da teoria do conhecimento e da compreensão crítica da lógica como ciência (LU,I,VII).

A teoria fenomenológica do sujeito e a análise da intencionalidade, às quais se dedica o segundo volume, não eram, pois, um agregado externo que se Ihe fazia ao antipsicologismo do primeiro (nem muito menos uma espécie de recaída, produto de uma inconseqüência) mas, pelo contrário, o complemento positivo necessário da sua crítica, a qual de modo algum estava finalizada simplesmente dizendo que há um mundo ideal e diferenciando o mesmo de toda realidade psicológica. Dado que uma análise psicológica

\footnotetext{
${ }^{11}$ Algo que ainda se lê nas histórias da filosofia e que, obviamente, não é certo. 12 "... so sah ich mich in immer steigendem Masse zu allgemeinen kritischen Reflexionen über das Wesen der Logik und zumal über das Verhältnis zwischen der Subjektivität des Erkennens und der Objektivität des Erkenntnisinhaltes gedrängt." (LU,I,VII)
} 
não pode fundar a objetividade da matemática, temos que separar de modo radical a objetividade do conteúdo conhecido da subjetividade do conhecer. Mas, uma vez que compreendemos o caráter necessário desta diferenciação, se coloca o novo problema de explicar o vínculo entre ambos. A crítica ao psicologismo e a revisão da teoria da subjetividade não se excluem, senão que se complementam e exigem reciprocamente.

\subsection{A influência de Frege e Brentano sobre Husserl}

As LU podem ser entendidas como uma síntese entre as filosofias de Frege e Brentano.

Frege é historicamente decisivo:
a) para o giro husserliano ao antipsicologismo;
b) para a tomada de consciência do novo problema pós antipsicologista; e
c) para o próprio caminho de solução que passa de modo essencial por uma forma específica de desenvolver a concepção intencional da cons- ciência.

No que diz respeito a Brentano, ainda que Husserl receba o conceito de intencionalidade do filósofo vienense, o impulso decisivo para colocar esse conceito em essencial relação à temática da apreensão da transcendência (lógica) vem de Frege. Em tal sentido, a questão fenomenológica não é uma questão pré-fregueana (um mastodonte que sobrevive à época glacial da crítica lingüística), mas uma questão pós-fregueana, uma conseqüência do desenvolvimento inerente ao realismo lógico. É a identidade tanto nos pressupostos básicos do problema quanto na solução, o que explica a longa série de similitudes, equivalências e paralelos entre Frege e Husserl que durante muito tempo foram constatados como meras curiosidades.

0 dito, porém, não significa que de Frege a Husserl nós temos uma mera explicitação. Três diferenças são decisivas:

1. Frege chega ao problema, Husserl parte dele.

2. Justamente por isso, existe entre ambos uma heterogeneidade de acento com respeito a esta nova questão, que de forma alguma deve ser subestimada: 0 centro de interesse de Frege era a luta antipsicologista; o de Husserl, a elaboração de uma teoria da subjetividade pós-psicologista.

3. Não menos importante é o fato de que nas LU o problema e a sua possível solução se apresentam com plena consciência da dificuldade metódica contida neles, tornando-se essencial a preocupação com 0 estabelecimento do marco adequado para o seu tratamento. Este marco tem que legitimar coisas tais como a possibilidade de efetuar a priori 
afirmações sobre a relação sujeito-objeto, algo que a psicologia empírica naturalista não deve e não pode: não pode, porque há aqui algo que não é psicológico; não deve, porque se ignoramos esse algo, caímos numa posição empirista e relativista. Do que se trata é de uma investigação de essências, ou seja, de um conhecimento a priori de objetos, porém, de objetos que têm justamente a ver com a relação sujeito-objeto, de Gedanken que têm a ver com a relação do sujeito e Gedanke. 0 método fenomenológico (para o qual se reclamará, em certo momento, estrita universalidade e, sobretudo, no qual se verá um caminho de "ir às coisas mesmas", aos "objetos - objetais") tem na sua origem um elo intrínseco com a temática da relação sujeito-objeto.

É no aspecto programático e metódico que a figura de Brentano surge como uma influência decisiva sobre Husserl. A discussão sobre o problema metódico do desenvolvimento de uma teoria a priori sobre a própria relação sujeito-objeto ${ }^{13}$ é tratado com profundeza e com exaustiva atenção de alternativas por Brentano, que evoluiria do inicial projeto de uma psicologia do ponto de vista empírico à proposta de uma psicologia descritiva.

\section{O Neokantismo}

\subsection{As escolas neokantianas}

Não podemos passar sem mais de Husserl a Heidegger se ignoramos um outro ator fundamental deste drama. Neste caso não se trata de um indivíduo, mas de uma escola, uma escola que dominou o panorama filosófico alemão durante quase cinqüenta anos: o neokantismo. Falar do neokantismo exige advertir contra dois equívocos:

1. A denominação "neokantismo" produz a crença de que os integrantes deste movimento eram sem mais "kantianos". Na realidade, 0 neokantismo não pretende ser uma mera interpretação, fiel à letra do texto kantiano, mas um desenvolvimento sistemático (certamente não arbitrário) a partir de Kant. É por isso que, às vezes, algumas das suas teses básicas surpreendem, pois eles não se sentem de modo algum comprometidos em preservar as doutrinas kantianas essenciais. Fora de discussão está, unicamente, o "método transcendental".

\footnotetext{
13 Sobre este ponto Frege não oferece respostas conclusivas.
} 
2. Existem duas escolas neokantianas principais, as quais possuem profundas diferenças entre si: a escola de Marburgo e a de Baden. Autores importantes da primeira são: Cohen, Natorp e Cassirer; da segunda, W indelband, Rickert e Lask. Como generalização, se pode dizer que Cohen e Windelband são os fundadores, Natorp e Rickert, o amadurecimento.

\subsection{As escolas neokantianas e o realismo lógico}

Para nosso tema, a precisão anterior é de vital importância, pois leva a situar o neokantismo em duas relações diferentes com o realismo lógico. $\mathrm{Na}$ origem da escola de Baden está a teoria de Lotze sobre a validez (Geltung) que, assim mesmo, não foi menos importante para Frege que para o jovem Heidegger. É por esta razão que ela está mais próxima do realismo lógico. Seus integrantes aceitam a existência de objetos ideais (os "valores"), entre os quais estão entidades "lógicas". A Escola de Marburgo afirma a existência de conhecimento a priori, mas sublinha que o único conhecimento a priori possível tem estrito caráter transcendental, ou seja, não é um conhecimento de "objetos", mas das condições da possibilidade de objetos. O neokantismo marburguês não se ocupa com objetos (lógicos, ideais ou de qualquer tipo), mas com a "objetividade", atendo-se firmemente ao princípio de que as condições da objetividade do objeto não podem ser pela sua vez objetos (lógicos ou não). Em tal sentido, os autores desta escola são contrários ao "platonismo" de Bolzano, Frege e a Escola de Baden, não menos que de Husserl.

Não obstante esta diferença fundamental, existem não menos essenciais coincidências entre as duas escolas neokantianas, as quais giram em torno ao seu comum rechaço do psicologismo. Na realidade, no mesmo ano em que Frege publica "Grundlage der Arithmetik" (1884), Cohen publica "Das Problem des Infinitesimalen und seiner Geschichte", uma obra de caráter eminentemente programático, cuja proposta é que a filosofia deve tornarse teoria da ciência. Seu tema é o conteúdo objetivo da ciência e a sua tarefa é refletir e explicitar as suas condições (lógicas) de possibilidade. Não precisa dizer que esse programa (sem o transfundo transcendental) possui pontos essenciais de similitude com Bolzano. 0 que difere é a terminologia. Assim como Bolzano diferenciava entre Wissenschafts- e Erkenntnislehre, Cohen haverá de diferenciar entre Erkenntniskritik e Erkenntnistheorie e, paralelamente à distinção Denken-Gedanke, entre Erkennen e Erkenntnis ${ }^{14}$. Em suma, a Erkenntniskritik se ocupa com 0

\footnotetext{
${ }^{14}$ Importante diferença que, não obstante, deve ser constatada a partir do fato de que o antipsicologismo neokantiano é essencialmente epistemológico e não semântico. A aparentemente elementar distinção entre sentido e valor de verdade, não joga papel decisivo
} 
conteúdo objetivo da ciência e não com a relação do mesmo a um sujeito psicológico. Como escrito fundacional da Escola de Baden pode ser considerado 0 artigo de Windelband "Über genetische und transzendentale Methode", o qual efetua uma proposta similar à coheniana. Em suma, a luta contra o psicologismo foi tão essencial para o neokantismo, quanto 0 foi para Frege, uma luta que, por outra parte, eles desenvolvem contemporaneamente. Se atendermos ao anterior, é compreensível o fato de que Natorp, frente à publicação das LU, se veja compelido a escrever lembrando que o neokantismo nada tinha a aprender de Husserl nesse ponto.

Ora, o neokantismo não tem em comum com as tendências mencionadas só 0 antipsicologismo, mas também, correlativamente, o problema da relação entre o objetivo e subjetivo, ao qual se vê conduzido pelo seu próprio desenvolvimento sistemático. 0 sujeito transcendental neokantiano, em especial em sua versão marburguesa, não era originariamente um sujeito, mas apenas um conjunto de condições lógicas, não existindo para uma "dedução transcendental" lugar algum. Mas, na medida em que a interpretação neokantiana vai purificando Kant de elementos "psicologizantes", amadurece a consciência de um novo problema que, em realidade, nós já conhecemos em uma outra variante: como se vincula o sujeito psicológico à esfera de idealidades transcendentais? Depois de tudo, ainda aceitando a necessidade de distinguir entre o conhecimento e o conhecer, uma fundamentação da possibilidade do conhecimento que conduza a impossibilidade do conhecer, é um sem sentido. Em termos gerais, podemos dizer que, em ambas escolas neokantianas, enquanto os fundadores tiveram como tarefa principal delimitar o problema transcendental do psicológico, a segunda geração tem como tarefa o elaborar uma teoria da subjetividade "real". Natorp publica seu esboço, "Einleitung in die Psychologie nach kritischer Methode", em 1888, e a versão definitiva, "Allgemeine Psycologie", em 1912. Rickert, por sua vez, publica o seu ensaio mais famoso sobre o tema, "Zwei Wege der Erkenntnistheorie, Transzendentalpsychologie und Transzendentallogik" em 1909. Em 1913, assim mesmo, aparece um artigo fundamental de Richard Hönigswald: "Prinzipien der Denkpsychologie". O problema do psicologismo termina conduzindo à busca de uma teoria da subjetividade e esta, por sua vez, a uma reflexão sobre a psicologia, isto é, à busca de alternativas aos modelos naturalistas dominantes identificados como base última do psicologismo.

algum na reflexão marburguesa. Em tal sentido, o fato que Cohen diferencie ErkennenErkenntnis ali onde Frege diferencia Denken-Gedanke, não é uma mera diferença terminológica, mas tem um valor simbólico especial: nesse ponto se evidencia uma radical heterogeneidade de perspectivas. 


\section{Dilthey}

Se, a partir da sua luta comum antipsicologista, neokantismo e realismo lógico enfrentam um problema similar, similitude não é identidade. A diferença se manifesta no fato de que, ao mesmo tempo em que 0 neokantismo ataca o psicologismo, é contra-atacado não só por este mas, assim mesmo, por uma filosofia que o coloca frente a novas exigências: "a filosofia da vida" (Lebensphilosophie) ${ }^{15}$.

Também Dilthey foi objeto da crítica antipsicologista (principalmente por parte de Rickert), vendo-se impelido a várias reformulações da sua doutrina inicial, a qual se manterá neste ponto em permanente evolução. No entanto, 0 ataque ao psicologismo diltheano, que não faz senão repetir argumentos já bem estabelecidos a mais um caso particular, não é agora 0 que interessa em primeiro lugar.

0 que interessa é que o problema do psicologismo se apresenta num plano aprofundado sendo, por dizer assim, absorvido pelo da psicologia: já não se trata de relacionar conhecer e conhecimento, pensar e pensamento, julgar e julgamento e sim o conhecimento e o sujeito "real". Em uma famosa passagem, que muito bem expressa esta nova situação, escreve Dilthey: "Nas veias do sujeito cognoscente que Locke, Hume e Kant construíram, não flui verdadeiro sangue, mas o suco diluído da razão como pura atividade pensante. Porém, a ocupação histórica e psicológica com o homem na sua totalidade me conduziu a colocar este ente que sente, experimenta e representa, na multiplicidade de suas capacidades, também na base do conhecimento" ${ }^{16}$. A relação cognoscitiva deve ser integrada na totalidade das relações vitais e pensada a partir dela. Disto se segue, a negaçãosuperação (Aufhebung) da idéia do eu como sujeito pensante ${ }^{17}$. 0 puro cogito, o sujeito transcendental, não são mais que meras abstrações a partir da complexa riqueza do verdadeiro eu. 0 vínculo primário e total do "eu" com a realidade não é de "representação" (vorstellen), como o expressa a relação "sujeito-objeto", mas sim de totalidade da vida ${ }^{18}$.

\footnotetext{
${ }^{15}$ A irrupção da Lebensphilosophie a partir da primeira guerra mundial é, geralmente, aceita como fator decisivo do declínio histórico do neokantismo.

16 "In den Adern des erkennenden Subjekts, das Locke, Hume und Kant konstruierten, rinnt nicht wirkliches Blut, sondern der verdünnte Saft von Vernunft als blosser Denktätigkeit. Mich führte aber historische wie psychologische Beschäftigung mit dem ganzen Menschen dahin, diesen in der Mannigfaltigkeit seiner Kräfte, dies wollende fühlende vorstellende Wesen auch der Erklärung der Erkenntnis... zugrunde zu legen". Wilhelms Dilthey Gesammelte Schriften, Leipzig-Berlin, 1921 ss. (GS). (GS, I, XVIII). Tr. do autor.

17 “...Aufhebung der Auffassung des Ich als Denksubjekt..." (GS,V,LVII)

18 "...ist aber nicht ein solches des Vorstellens, wie die Relation von Subjekt zum Objekt es ausdrückt, sondern ein solches des ganzen Lebens." (GS,VIII,141)
} 


\section{Heidegger}

\subsection{A crítica do psicologismo}

Em 1912, Heidegger publica "Neuere Forschungen über Logik", onde mostra estar atento ao desenvolvimento acontecido na lógica do séc. XIX e possuir uma avaliação em extremo positiva do mesmo. Em tal contexto, existe uma referência a Frege, caída no esquecimento ${ }^{19}$, porém, sem dúvida de extrema importância, tanto mais para quem se lembra que Heidegger estudou matemática e que esteve em dúvida a respeito do seu tema de habilitação (que originariamente seria o número), o que abertamente deixa ver as suas simpatias com respeito a uma teoria logicista. $\mathrm{Na}$ verdade, o mencionado tema não despertou entusiasmo em Rickert, o qual, contra o que era a tendência majoritária no neokantismo, defendia uma teoria não-logicista do número. 0 escrito de 1912 documenta um interesse não superficial pela evolução da lógica, ainda que o grau de familiaridade de Heidegger com a mesma não seja dos melhores ${ }^{20}$.

0 artigo sobre a lógica "contemporânea" serviu a Heidegger de base para a sua dissertação: "Die Lehre vom Urteil im Psychologismus". A idéia fundamental deste escrito é que, se o psicologismo morreu, ele pode reviver a qualquer hora, ou seja, que ainda temos que colocar cadeados na tampa do caixão para não levar um susto. 0 ponto central no qual é ainda necessário insistir, dado que o trabalho efetuado até agora pode não ser suficiente, é a teoria do juízo ${ }^{21}$. A Dissertação heideggeriana propõe uma crítica à concepção psicologista do juízo em alguns de seus representantes, assim como uma proposta positiva na qual possui um papel decisivo a retomada do conceito lotzeano de validez (Geltung).

19 "In diesem Zusammenhang möchte ich den Namen eines deutschen Mathematikers nicht unerwähnt lassen. G. Freges logisch mathematische Forschungen sind meines Erachtens in ihrer wahren Bedeutung auch noch nicht gewürdigt, geschweige denn ausgeschöpft. Was er in seinen Arbeiten über Sinn und Bedeutung, über Begriff und Gegenstand nidergelegt hat, darf keine Philosophie der Mathematik übersehen. Es ist aber auch im gleichem Masse wertvoll für eine allgemeine Theorie des Begriffes. Wenn Frege dem Psychologismus im Prinzip wohl überwand, so hat doch Hussserl erst in seinen Prolegomena zur reinen Logik das Wesen, die relativistischen Konsequenzen und den theoretischen Unwert des Psychologismus systematisch und umfassend auseinandergelegt." (NFL, 20)

${ }^{20} \mathrm{~A}$ verdadeira fonte de muitas idéias que Heidegger, falsamente, atribui ao logicismo, são os escritos "propagandístico - didáticos" de Couturat, que na apresentação sucinta da "logística" começa com o cálculo sentencial, o que é sem dúvida correto. É isso, porém, o que leva a Heidegger a pensar que a nova lógica carece de uma reflexão sobre o juízo.

${ }^{21}$ Num próximo artigo me proponho a desenvolver este ponto por extenso. 
O escrito juvenil do autor de "Ser e tempo" pode ser analisado de forma imanente, colocando o acento seja na sua perspectiva crítica, seja na sua proposta construtiva. Porém, tal ponto de vista exige pré-condições que ainda não têm sido cumpridas como, em particular, um esclarecimento suficiente da noção lotzeana de Geltung, a qual é mencionada e descrita amiúde, mas não propriamente analisada. É por isso que, como indicamos no começo, assumiremos um método comparativo, pois aqui sim, os prérequisitos estão presentes.

Ora, no que respeita a tarefa de contextualizar o trabalho heideggeriano (e pressuposto o panorama que temos desenvolvido), deve se dizer que chamam a atenção duas significativas ausências:

1. Heidegger incorre, sem dúvida, em erro quando afirma que a crítica ao psicologismo carece de uma teoria adequada do juízo e, por tal motivo, exige ser completada em tal direção. É óbvio que a leitura de Lask foi determinante para tal convicção. Porém, Heidegger passa por alto 0 fato de que tanto Bolzano quanto Frege desenvolveram teorias a este respeito totalmente elaboradas, que, pelo menos, deveriam ser discutidas antes de qualquer novo intento.

2. Heidegger, como tantos outros antipsicologistas epigonais, chega tarde à festa e avalia incorretamente 0 status questiones ${ }^{22}$.

\subsection{Crítica ao psicologismo e subjetividade transcendental}

0 texto heideggeriano se concentra na crítica ao psicologismo e diz pouco ou nada sobre a questão que na elite neokantiana era tema central, a saber, a elaboração de uma teoria da subjetividade pós-psicologista. Esta situação se manifesta de várias formas.

- Todo o escrito de Heidegger está centrado no problema do Urteil. Rickert acaba de escrever um artigo, "Juízo e julgar" ("Urteil und Urteilen", 1912), estabelecendo (ou, mais propriamente, re-estabelecendo na perspectiva de Baden), uma diferença decisiva no juízo entre o conteúdo julgado e 0 ato de julgar, à qual ele acopla uma sistemática de diferenciações (Urteilssinn, Urteilsgehalt etc.). Heidegger menciona 0 artigo referido, mas não 0 analisa, com a desculpa de que só vai tratar de autores psicologistas que necessitam de correções e não daqueles que já estão livres da doença. A desculpa não poderia ter sido mais retórica.

\footnotetext{
22 O centro de interesse da Dissertatio heideggeriana é o problema do juízo enquanto problema lógico. Nada autoriza, neste texto, a entrever a questão de um aprofundamento ontológico como necessária. Se nos ativermos às manifestações expressas do próprio Heidegger, é a partir do final da monografia sobre Duns Scoto e, em relação direta com dificuldades na teoria de negação, que surge essa inquietude. Veja-se: Martin Heidegger - Heinrich Rickert. Briefe 1912-1933. Frankfurt, Vittorio Klostermann, 2002. pp. 25, 34, 48-49.
} 
- A crítica que Heidegger dirige à teoria do juízo de Brentano mostra pouca familiaridade com 0 autor. Ela parece estar baseada só naqueles textos da "Psicologia do ponto de vista empírico" que anunciam de modo expresso tratar desse tema. Heidegger não conhece outros textos brentanianos pertinentes ao problema (e que evidenciam uma reflexão em extremo dinâmica sobre o mesmo), nem as complexas variações que sofre a teoria de Brentano (que passa inclusive por posições similares às que ele mesmo está querendo defender). Além disso, não há uma única referência ao conceito de intencionalidade.

- Muito pobre e injusta é a análise de Lipps, que proporciona a imagem distorcida de um autor inexpressivo quando, na realidade, se trata de uma figura digna de atenção mais detida, pelo menos por dois motivos: primeiro, porque explora de modo sistemático os pontos fortes do psicologismo e parte para 0 ataque, nem sempre errando 0 alvo; segundo, porque ele evolui na sua posição passando do psicologismo ao antipsicologismo, e por tal motivo, seus textos constituem um complexo mostruário dos argumentos e contra-argumentos que eram empregados por uma e outra tendência.

- A escola de Marburgo é lembrada só no seu antipsicologismo, não havendo referência a Natorp e outros neokantianos de valia.

- Em geral, a referência a Husserl é só ao primeiro volume das LU, que parece ser 0 texto que Heidegger até então estudou seriamente. Nenhuma outra referência a esta obra testemunha uma familiaridade maior, com uma importante exceção.

Uma vez que, ao longo de todo o livro, se insiste em separar o plano lógico e o psicológico, inesperadamente, Heidegger parece lembrar que também há um problema que diz respeito ao vínculo entre ambos e sugere, sem maiores detalhes, que a resposta para esse problema deve-se buscar apelando a algum tipo de sujeito transcendental. Esse sujeito transcendental, com certeza, não é o kantiano, mas tem fontes mais imediatas. Essa fonte não é, porém, o neokantismo de Marburgo (para o qual o sujeito transcendental foi mais um problema que uma solução). Ela poderia ser Rickert, mas a explícita referência a Husserl não deixa aqui subsistir dúvida alguma. A importância dessa referência a Husserl põe-se em evidência, é coerente e se corrobora de modo recíproco, com outro texto fundamental.

\subsection{A faticidade do Dasein como verdadeira transcendentalidade}

Após a Dissertatio sobre o psicologismo e a habilitação sobre Duns Scoto, temos um vácuo nas publicações de Heidegger. 0 que nos interessa agora é (pelo menos) tornar plausível o que esse vacuum representou do ponto 
de vista do tema do psicologismo. Sabemos que nestes anos se processa 0 surgimento do SZ e que nesta obra a discussão com Husserl joga um papel decisivo. Sabemos, assim mesmo, que SZ é incompreensível sem um novo conceito de transcendentalidade e de faticidade. Sabemos, ainda mais, que SZ não é nem psicologia, nem antropologia e que a teoria do juízo tradicional experimenta nessa obra uma reformulação radical. Mas, e o psicologismo? E o antipsicologismo? É a tarefa de uma teoria da subjetividade pós-psicologista?

Neste ponto, parece que estamos frente a um hiato, onde faltam todos os passos intermediários. Reconstruir os mesmos seria, sem dúvida, uma importante tarefa, caso eles efetivamente existissem ${ }^{23}$. Porém, no presente trabalho me limitarei a apontar esta questão como puro limes da minha análise. 0 essencial está claramente exposto em algumas linhas que Heidegger escreveu no contexto de seus comentários críticos ao artigo de Husserl sobre fenomenologia destinado à "Enciclopédia Britânica". Mas, para que esse texto seja compreensível, lembremos uma distinção chave para "Ser e Tempo", a saber, a distinção entre faticidade (Faktizität) e fatualidade (Tatsächlichkeit) (SZ,135). Existem dois "que" ("dass"). Um é o dass daquilo que pertence ao subsistente (Vorhandenheit) ${ }^{24}$ e é categorialmente determinado. Este é acessível em um constatar através de uma simples olhada ("um hinsehendes feststellen"). Agora, faticidade não é a positividade do factum brutum de um algo simplesmente presente (vorhanden), senão um caráter do Ser do Dasein, que é compreendido na

\footnotetext{
${ }^{23}$ Não é improvável que aqui estejamos frente a uma verdadeira "Umkippung", na qual Dilthey foi decisivo.

24 "Vorhandenheit" já têm sido traduzido por "subsistência", "ser aos olhos", "presentemente dado", "simplesmente dado", "ser disponível", etc.. Quiçá a tradução por um único termo em todos os contextos, não seja recomendável. No contexto atual, usei "subsistência", "simplesmente presente" e "presente". No primeiro caso, fundei a minha opção na possibilidade de contrapor, tanto em alemão quanto em português, Subsistenz - Existenz ou subsistência - existência; no segundo, na possibilidade do "vorhanden" de ser intuído. Vinculo o "vorhanden" ao "vorfindlich" e obtenho assim a possibilidade de reproduzir o sugerido na oposição "vorfindlich" - "befindlich". Heidegger se vale da diferença entre finden, vorfinden e sich befinden. Nos três casos, trata-se de um encontrar, porém só no primeiro caso isto acontece sem mais. Eu só posso "encontrar" (finden) algo que perdi, que busco ou que anteriormente não tinha percebido. No segundo, trata-se de um encontrar algo que está diante de mim. O encontrar da Befindlichkeit é sempre um encontrarse (sich befinden). Ora, é obvio que eu não posso me perder e, em conseqüência, me encontrar no primeiro sentido, mas tampouco eu posso me encontrar "frente" a mim mesmo, como algo diferente de mim. Na verdade, eu não me encontro no sentido de encontrar em nenhum dos dois primeiros casos, mas no sentido em que "se encontrar" supõe sempre "em uma certa forma", ou seja, se trata do sentido de encontrar no qual eu, por ex. pergunto: como você se encontra? e espero como resposta algo assim como "bem", "mal", "triste", etc.. O Dasein se encontra sempre em um certo estado (de ânimo) (Stimmung), e só nele é que ele se encontra ou se dá a si mesmo. O exposto nesta nota não pretende esgotar o tema, e sim, tão somente, dar uma idéia preliminar dos sentidos dos termos alemães e dos usos que Heidegger faz deles que possibilite a compreensão do texto central.
} 
existência (Existenz), ainda que primeiramente (de um modo) "forçado". 0 "quê" dela não se encontra jamais no mero intuir $(S Z, 135)^{25}$. 0 Dasein não é simplesmente encontrável (vorfindlich) na intuição (Anschauung), pois ele não é simplesmente presente (vorhanden), mas ele se encontra de um certo modo (é befindlich). Tendo presente agora a diferença entre Tatsächlichkeit e Faktizität, Ieiamos a decisiva passagem anunciada, com a qual concluo este escrito: É claro, diz Heidegger, “... que o ente, no sentido daquilo que eles chamam mundo, não pode ser aclarado em sua constituição transcendental através de um regresso a um ente que possua esse mesmo tipo de ser... Por isto, se deve referir a problemática do ser de um modo universal tanto ao constituinte como ao constituído... Trata-se de mostrar que o modo de ser próprio da existência humana é totalmente diferente do de todo outro ente e que ele, enquanto aquele que ele é, contém justamente em si a possibilidade de constituição transcendental. A constituição transcendental é uma possibilidade central da existência do si mesmo (Selbst) fático. Este, o homem concreto enquanto tal, ou seja, enquanto ente (als Seiendes), não é jamais um fato real intramundano, pois 0 homem não meramente subsiste (vorhanden) ${ }^{26}$, senão que existe (existiert). E o "maravilhoso" é que o modo de ser do Dasein possibilita a constituição transcendental de todo o positivo" ${ }^{27}$.

Endereço do Autor:

Rua Anastácio de Souza Pinto 333, apt. 142 - Freguesia d'0

02926-030 São Paulo - SP

E-Mail: mariopor@pucsp.br

$25 \mathrm{Tr}$. do autor: "Faktizität ist nicht die Tatsächlichkeit des factum brutum eines Vorhandenen, sondern ein in die Existenz aufgenommene, wenngleich zunächst abgedrangt Seinscharakter des Daseins. Das dass der Faktizität wird in einem Anschauen nie vorfindlich."

${ }^{26}$ Ou: “... o homem não é simplesmente (ou meramente) presente..."

${ }^{27} \mathrm{Tr}$. do autor: “... dass das Seiende im Sinne dessen, was sie Welt nennen, in seiner transzendentalen Konstitution nicht aufgeklärt werden kann, durch einen Rückgang auf Seiendes von ebensolcher Seinsart... Universal ist daher das Problem des Seins auf Konstituierendes und Konstituiertes bezogen... Es gilt zu zeigen, dass die Seinsart des menschlichen Daseins total verschieden ist von der alles anderen Seienden, und dass sie als diejenige, die sie ist, gerade in sich die Möglichkeit der transzendentalen Konstitution birgt. Die transzendentale Konstitution ist eine zentrale Möglichkeit der Existenz des faktischen Selbst. Dieses, der konkrete Mensch, ist als solcher - als Seiendes - nie eine weltlich reale Tatsache, weil der Mensch nie nur vorhanden ist, sondern existiert. Und das 'Wundersame' liegt darin, dass die Existenzverfassung des Daseins, die transzendentale Konstitution alles Positiven ermöglicht." Biemel, W.: "Husserls Encyclopedia Britannica Artikel und Heideggers Anmerkungen dazu". Tijdschrift voor Filosofie, 12, 246-280, 1950. 